\title{
Design, Simulation, Implementation and Control of Digital Self-Compensating Method for Integral Cycle Power Control for Welding Application
}

\author{
N. D. Mehta ${ }^{1}$, Dr. D. K. Bhatt ${ }^{2}$ \\ ${ }^{1}$ Assistant professor in Power Electronics Department at VGEC, Chandkheda Ahemadabad, India \\ ${ }^{2}$ Assistant Professor, Electrical Engineering Department of VGEC, Chandkheda Ahemadabad, India
}

\begin{abstract}
The Class of ac power controllers consists of Solid State Power Controller (SSPC) which connects and disconnects the load to the supply according to the required power. Two important voltage control techniques are commonly used for heating power control in ac power controller are Phase Control Switching (PCS) and Integral Cycle Control (ICC). In case that a PCS is used for the resistive load, it can produce higher order harmonics and heavy inrush current while switching on in a cold start. A feedback controlled digital circuit which provides for ICC of power in R-L loads is described. The significant feature of the circuit is that it rapidly and automatically adjusts the firing angle of the Power Semiconductor Device (PSD) to eliminate the undesirable dc component in the current of RL loads. Another notable feature of the circuit is that the initial conduction is started with firing angle $\alpha=90^{\circ}$ which results in suppressed first peaks in the conduction bursts. Subsequently, the feedback takes over to make the firing angle at equal to the power factor angle $\Phi$, thereby triggering conduction at the current zero in each burst. This scheme of automatic dc offset elimination can be utilized to good advantage in the case of motor loads with rapidly changing power factors. The circuit is simple, inexpensive, and can be assembled easily using commercially available components. In the proposed method, a disadvantage of phase controlled is removed. In this paper authors have reported simulated results, design methodology and implementation of the ICC method for Welding application for R-L load.
\end{abstract}

Keyword: Burst Firing, Heating Application, Integral Cycle Control (ICC), Pulse Burst Modulation (PBM), Digital Self Compensation.

\section{Introduction}

Basically, two types of ac - to - ac conversion are in use direct conversion and indirect conversion. In indirect ac- ac conversion involves an intermediate dc stage, called the dc link or dc bus and the converter are called the dc - link converter. During direct conversion the ac input waveforms are directly converted into the desired output waveforms. Phase controlled Switching (PCS) is one of the method of the direct conversion. PCS is extensively used for adjustable ac-to-ac and ac-to-dc power conversion [1]. In case of heat controllers of resistive load (R), phase control circuits cause higher order harmonics and generate Radio Frequency Interference (RFI) and heavy inrush currents while switching on from cold. At large power levels, it requires bulky and expensive line filters to minimize RFI [2]. In the case of PCS, the rms value of output voltage $\left(\mathrm{V}_{0}\right)$ and Power Factor (PF) are given by [3]. Fig. 1 (a) shows the switching arrangement of phase control circuit.

$$
\begin{gathered}
\mathrm{V}_{\mathrm{O}}=\mathrm{V}[1 / \pi\{(\pi-\alpha)-1 / 2 \sin 2 \alpha\}]^{1 / 2} \\
\mathrm{PF}=\mathrm{V}_{\mathrm{O}} / \mathrm{V}
\end{gathered}
$$

where input supply voltage $v(\mathrm{t})=\mathrm{V}_{\mathrm{m}} \sin \omega \mathrm{t} ; \mathrm{V}_{\mathrm{m}}$ and $\mathrm{V}$ are maximum and rms values of the supply voltage and $\alpha$ is the switching angle of the circuit, as shown in Fig. 1(b). The expression of Total Harmonic Distortion (THD) is given by [3]

$$
T H D=\frac{\sqrt[n]{\sum_{z} n}}{I 1}
$$

Where I is the fundamental value of the line or input supply current and $I_{i}$ are represents the harmonic current components of I. When $\alpha$ varies between 60 and 120, the supply voltage is close to its Peak value $(86.7 \%$ to $100 \%)$ and the corresponding voltage control range is from $44.2 \%$ to $89.7 \%$. At the switching instant $(\omega t=\alpha)$, the line current jumps from zero to almost its peak value, as shown in Fig. 1(b).

Thus, di / dt is high over a wide range of control. Moreover, there is heavy inrush current when furnace element $\mathrm{R}$ is heated from cold (due to high temperature coefficient of resistance of the element). At a higher value of $\alpha, \mathrm{PF}$ is also low and THD is significantly high, as shown in Fig. 2.

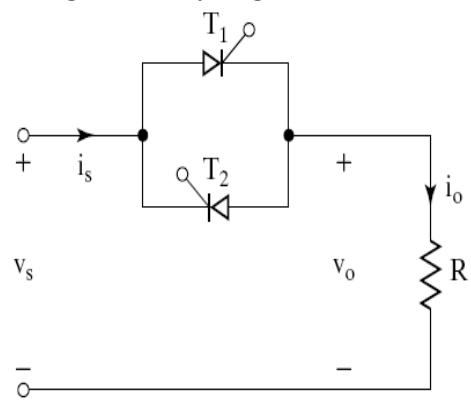

(a)

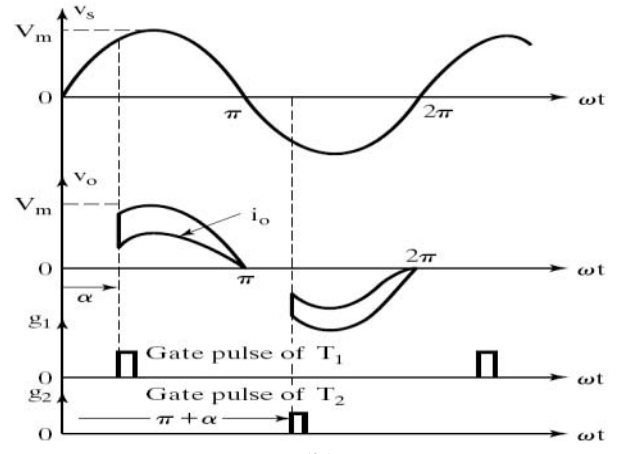

(b)

Figure 1: (a) Switching arrangement of phase control circuit 


\section{International Journal of Science and Research (IJSR) \\ ISSN (Online): 2319-7064}

Index Copernicus Value (2013): 6.14 | Impact Factor (2014): 5.611

(b) Waveforms of phase control circuit

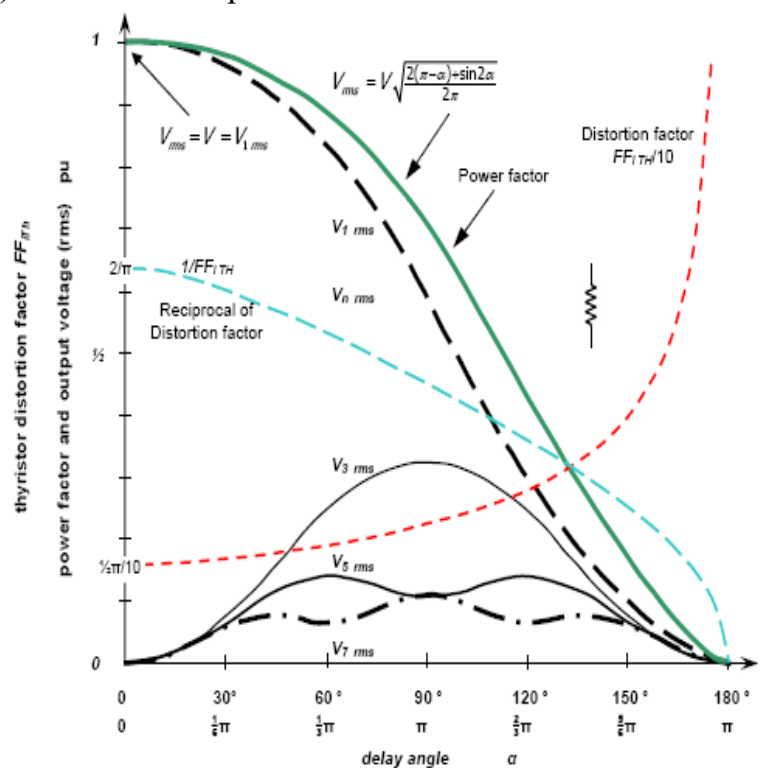

Figure 2: Variation of PF, THD with Switching angle $\alpha$ in Deg

\section{Principle of Operation}

ICC is used for controlling power to an ac load by permitting few full cycles to power the load followed by off period. This is repeated cyclically. The duty cycle is controlled for changing the output power basically it is an on - off control similar to the obtained through thermostatic switches except that here an integral number of cycle are passed. In literature, ICC is also described as On - Off control, Burst firing, Zero Voltage Switching (ZVS), Cycle Selection and Cycle Syncopation [4]. Fig. 3 shows the output voltage waveform of Integral cycle controller. When the power is $\mathrm{ON}$, during $\mathrm{N}$ cycle the speed or temperature increases exponentially from a minimum value and reaches a maximum at the end of the $\mathrm{N}^{\text {th }}$ cycle. If $\mathrm{N}$ us the number of full cycles passed per $M$ cycles of the source voltage then it is said to have a duty cycle of $\mathrm{D}=\mathrm{N} / \mathrm{M}$. The difference between maximum of temperature and the minimum temperature is called the differential.

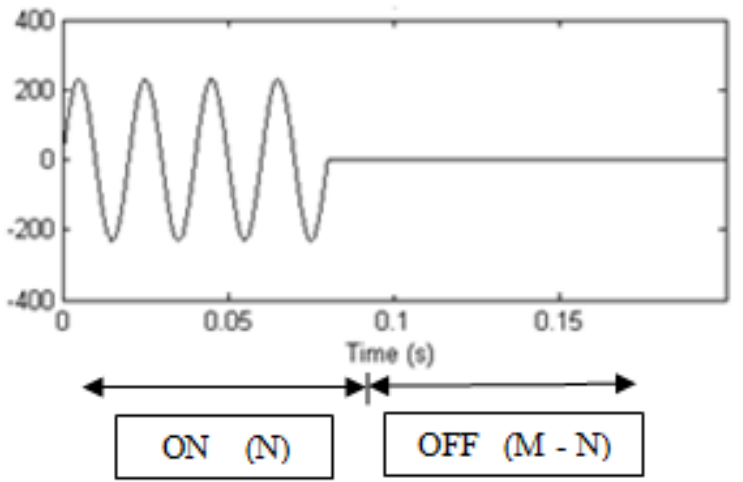

Figure 3: Output of Integral Cycle Controller

If $\mathrm{M}$ is increased their differential increases and vice versa. Low value of $\mathrm{M}$ limit the variation in the value of $\mathrm{N}$, as the smallest power available is

$$
\begin{array}{ll}
\mathrm{P}_{\min }=\left(\mathrm{Vs}^{2}{ }^{*} 1\right) / \mathrm{M} * \mathrm{R} & \text { when } \mathrm{N}=1 \\
\mathrm{P}_{\max }=\mathrm{Vs}^{2} / \mathrm{R} & \text { when } \mathrm{N}=\mathrm{M} \\
\text { Control Ratio }(\mathrm{CR})=\mathrm{P}_{\max } / \mathrm{P}_{\text {min }}=\mathrm{M}
\end{array}
$$

The CR is independent of $\mathrm{N}$ but depends on $\mathrm{M}$. ICC gives a much higher differential than phase control. Therefore it can be applied only to those processes where the process time constant is large, which keeps the differential low and higher value of $\mathrm{M}$ can be Chosen. Average power consumed by the load can be varied by Changing $N$ keeping $M$ fixed, Changing $\mathrm{M}$ keeping $\mathrm{N}$ fixed or changing both. Fig. 4 shows the variation of power and power factor for an ICC in terms of controlled load.

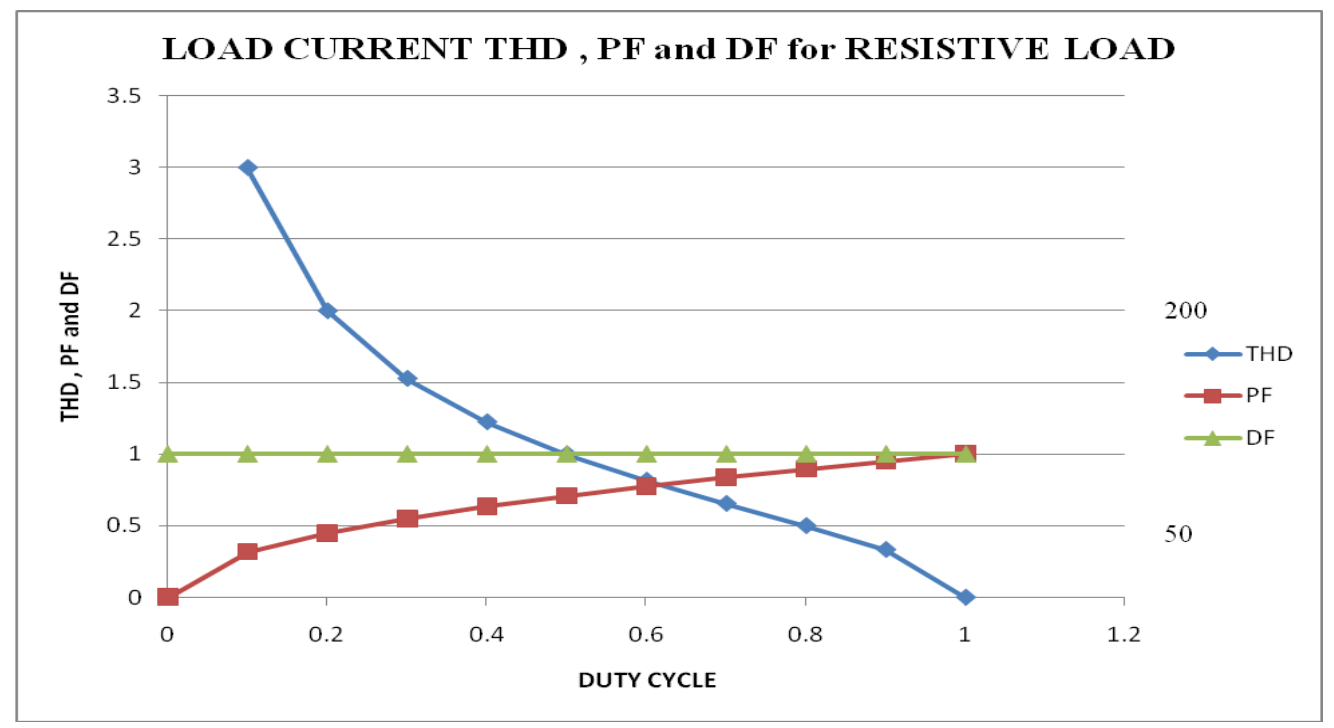

Figure 4: Variation of RMS value and PF

The current in an R-L load subjected to ICC will contain a transient component ( $\mathrm{dc}$ offset), in each conduction burst if the PSD firing angle $\alpha$ is not equal to the power factor angle $\Phi$. On the other hand, if $\alpha$ is made equal to the power factor angle $\Phi$ of the load, the dc offset transient in the current vanishes. This objective must eventually be achieved by the control circuit automatically. However, initially, before the feedback circuit has been fully activated, some choice has to 


\section{International Journal of Science and Research (IJSR) \\ ISSN (Online): 2319-7064 \\ Index Copernicus Value (2013): 6.14 | Impact Factor (2014): 5.611}

be made of the angle $\alpha$. The two obvious choices are $\alpha=0^{0}$ and $\alpha=90^{\circ}$. Given a certain load power factor angle $\Phi$ lagging, the feedback circuit should shift the angle either forward from $0^{\circ}$ to $\Phi$ or backward from $90^{\circ}$ to $\Phi$. To make a judicious choice of the initial a the general expression for the current in an RL load subjected to sinusoidal excitation is taken

$$
i=\frac{V_{m}}{Z}\left\{\sin (\omega t-\emptyset)-\sin (\alpha-\emptyset) e^{(\cot \emptyset)(\alpha-\omega t)}\right\}
$$

Where

$\mathrm{V}_{\mathrm{m}} \sin \omega \mathrm{t}$ supply voltage,

$\mathrm{Z}\llcorner\Phi$ load impedance,

$\alpha$ triac firing angle with respect to the voltage zero.

The second term in the current expression represents the transient dc offset. This term could add or subtract from the first peak of the first term depending upon the value of $\alpha$ chosen. Fig. 5(a) and (b) shows the offset in the load current at initiation for a power factor angle $\Phi=40^{\circ}$ lagging. It is clear that for $\alpha=0^{0}$ the first peak of the load current is much higher than either the first or subsequent peaks of the load current for $\alpha=90^{\circ}$. Hence it was considered preferable to start the first burst of conduction at $\alpha=90^{\circ}$. It is apparent that any feedback circuit that would make the system self compensating, that is, eliminate the dc offset, would have to sense the magnitude of the dc offset in each burst of

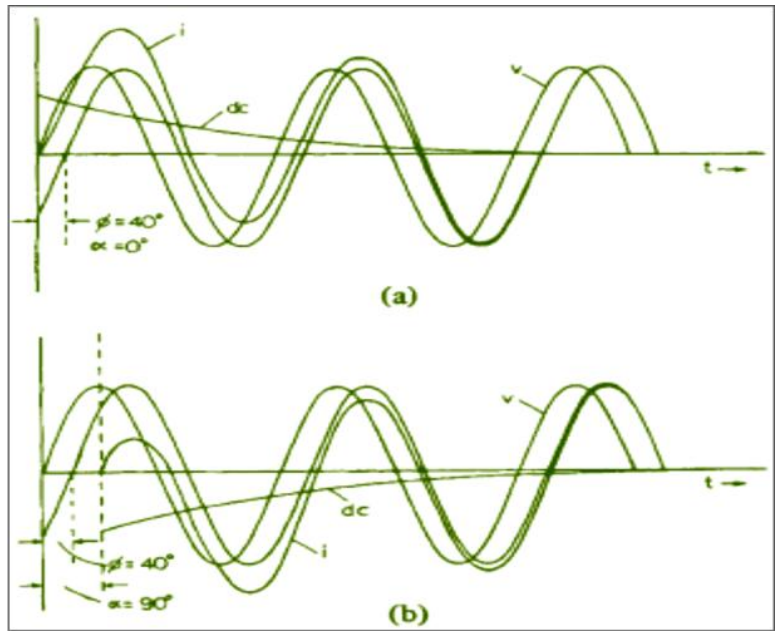

Figure 5: (a) Waveforms of voltage and current for R-L load $\varphi=40^{\circ}, \alpha=0^{0}$. (b) Waveforms of voltage and current for R-L load $\varphi=40^{\circ}, \alpha=90^{\circ}$.

conduction. This sensing could be achieved by any averaging technique. Once a dc signal proportional to the load current wave is extracted, it can be used as a negative feedback signal to shift the firing angle $\alpha$ from an initial value of $90^{\circ}$ to $0^{\circ}$. Keeping in mind the present trend towards using the more compact Integrated Circuits (IC's) in preference to discrete elements, it was considered advisable to develop a control circuit which was fully digitized using commercially available

IC components.

\section{Performance Characteristic}

SSPC is modeled as an ac voltage source or current source connected to a load through a network of switches. Switches including diode are assumed to be ideal and unidirectional, zero on state losses and unrestricted voltage or current carrying capabilities for a simplified analysis and the criteria for measuring the performance of the converter operation.

The steady state converter performance measures can be put into four categories: Voltage Transfer Ratio (VTR), Current Reflection Ratio (CRR), harmonic profile, component stresses.

VTR: The forward voltage transfer ratio is defined as the ratio of the rms voltage output voltage to the rms input voltage.

CRR: The reflective characteristic gives the effect of load current on the current drawn by from the source. The CRR is defined as the ratio of the input current to the rms load current.

Harmonic Profile: The output voltage and source current wave form are non sinusoidal. The lowest undesired harmonic frequency in the voltage and input power factor are the measures used for the undesirable Fourier Component.

Component Stresses: Voltage and current in the switch may consist of high transient which may be considering higher than the normal operating voltage. These transients voltage dictate the selection of switching devices and hence determine the cost. The component stress is measured as the ratio of the peak Voltage (Current) to the rms value of the components.

\section{System Design}

\section{A. Block Diagram}

Block Diagram of ICC circuit involves the basic three sections. First section comprises of a power supply stage to drive all internal amplifier and feed the gate energy to the power semiconductor devices. In second section a zero voltage detecting stage, which sense the instant of zero supply voltage.

This stage releases the power amplifier for a short duration pulse this cross over point so that they may trigger the power semiconductor if required or separate some other more continuous drive circuit.

Finally in third section an amplifier stage is required which magnifies the control signal to provide the drive needed to turn on the power switch on. As shown in the block diagram, the control block consists of control circuit for the ICC, Firing Circuit and Power Amplifier (FCPA) and power supply for controlling the load.

FCPA consist of the gate driver for thyristor and triac is used as power devices in the proposed design. 
International Journal of Science and Research (IJSR)

ISSN (Online): 2319-7064

Index Copernicus Value (2013): 6.14 | Impact Factor (2014): 5.611

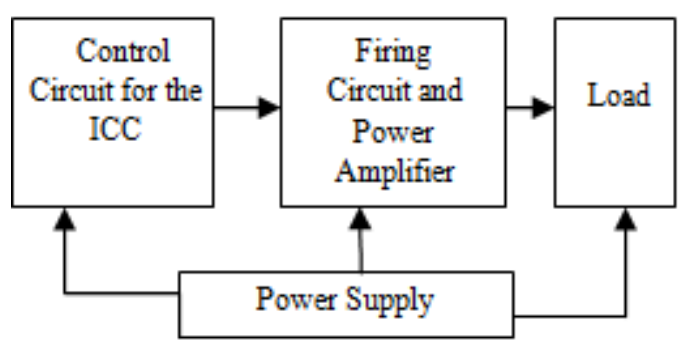

Figure 6: (a) Block Diagram of the ICC

\section{B. Simulation}

Simulation of ICC using MATLAB Simulink has been carried out by the authors and results are discussed for the various duty cycles. Fig.6 (b) shows the simulation result for ICC for the circuit topology discussed in Fig. 6 (a). Simulation is carried out in MATLAB R2006 with simulation parameter configuration of fixed step type ODE 4 type (Runge-Kutta) with unconstrained Periodic Sample time of fixed step size of 1e-6.
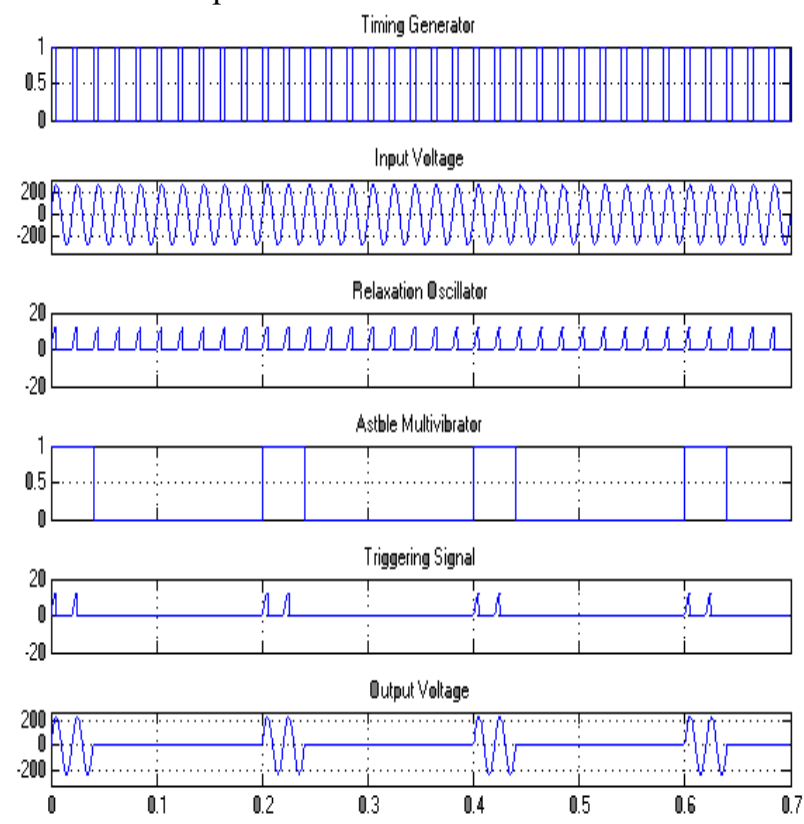

Time offset: 0

Figure 6: (b) Simulation result for the control topology of ICC

MATLAB program have been developed to calculate the power factor, harmonic profile of the output waveform up to 16 fo where fo is the output frequency. [5]

\section{// MATLAB Programme for Integral Cycle Control //}

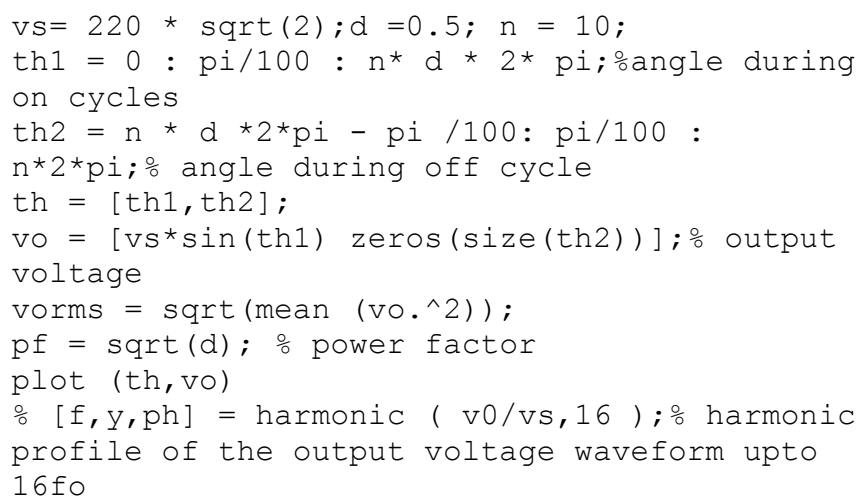

Figure 6: (c) describes the output voltage waveform in ICC with duty cycle $\mathrm{D}=0.2$ and harmonic profile.
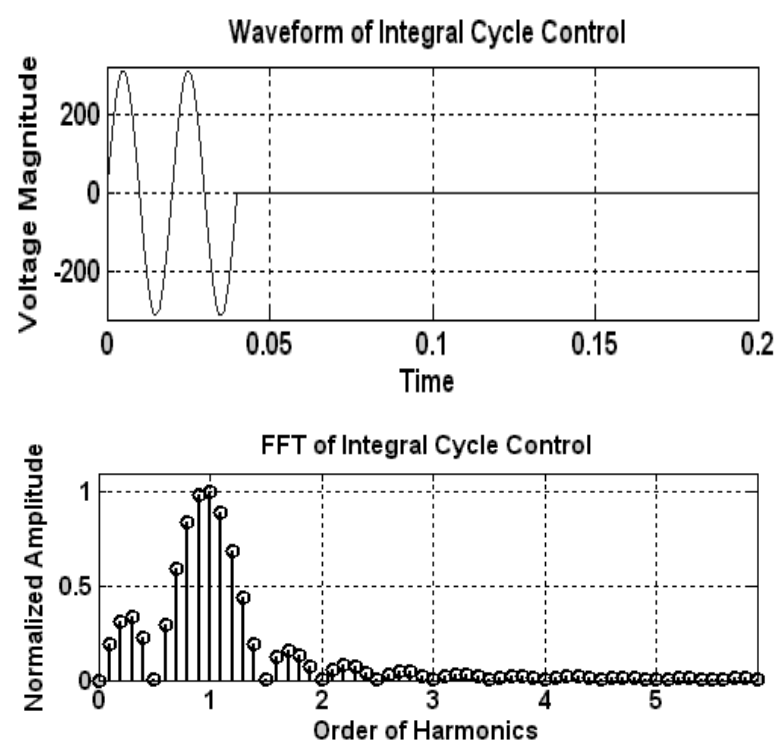

Figure 6: (c) Output Voltage in ICC with $\mathrm{D}=0.2$ and harmonic profile

There are some general conclusions about the harmonics from simulations:

- The minimum frequency is $\mathrm{f} \mathrm{i} / \mathrm{M}$ and components occurs at an integer multiple of minimum frequency.

- There are no integer harmonics of fo and above fo.

- The amplitude of fundamental is always dependent on D and no phase shift occurs in the fundamentals (fo) current component.

- The amplitude of each frequency component is depends on the switching frequency.

\section{Hardware}

The block diagram of Fig. 7(a) shows the principal stages in the circuit while Fig. 7(b) shows the detailed schematic. The design centers around the SN74191 Synchronous Up/ Down Counter programmed for up counting from 8 to 15 . The output of the SN74191 goes through appropriate gates to a single pole eight position switch such that any desired conduction period from one cycle to eight cycles could be obtained. For control periods other than eight cycles, the switching logic could be changed. Fig. 8 shows the signals at different stages in the control circuit programmed for a conduction period of five cycles out of eight. Pulse trains $\boldsymbol{A}$ goes through an RC coupling network which was found necessary for the elimination of high frequency noise generated in the comparator $\mu \mathrm{A} 710$. The output $\boldsymbol{D}$ of the eight position switch is delayed through an RC circuit and subsequent Schmitt Triggers so as to obtain the correct $90^{\circ}$ delay between signals $\boldsymbol{D}$ and $\boldsymbol{F}$. The delayed signal $\boldsymbol{F}$ could have been connected directly to the second stage of the Gate Drive circuit. If this was done, the trailing edge of $\boldsymbol{F}$ which extends beyond that of $\boldsymbol{D}$ might cause the triac to conduct an additional half cycle beyond the desired number of cycles $\boldsymbol{Q}$. But with the circuit arrangement shown, the gate firing signal $\boldsymbol{G}$ has a trailing edge which is coincident with that of $\boldsymbol{D}$ resulting in complete elimination of any possible halfcycle conduction beyond $\boldsymbol{Q}$ cycles. 
International Journal of Science and Research (IJSR)

ISSN (Online): 2319-7064

Index Copernicus Value (2013): 6.14 ! Impact Factor (2014): 5.611

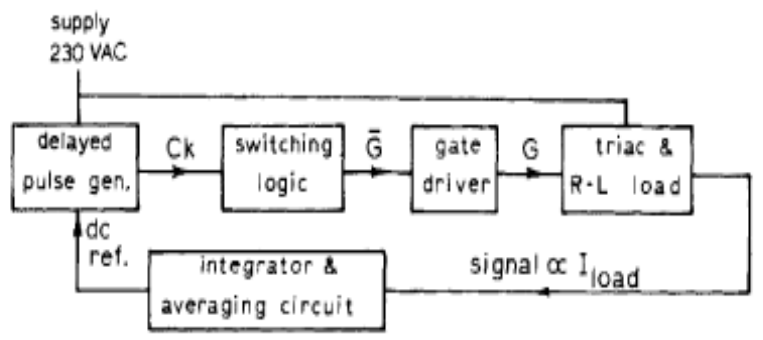

(a)

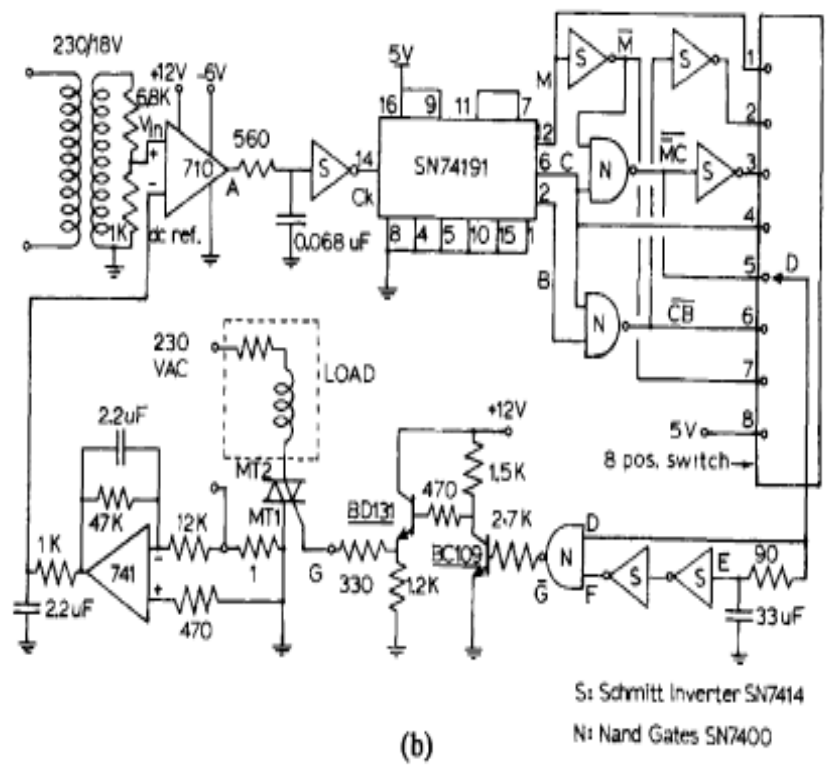

Figure 7: (a) Power control system block diagram. (b) Power control circuit schematic diagram.

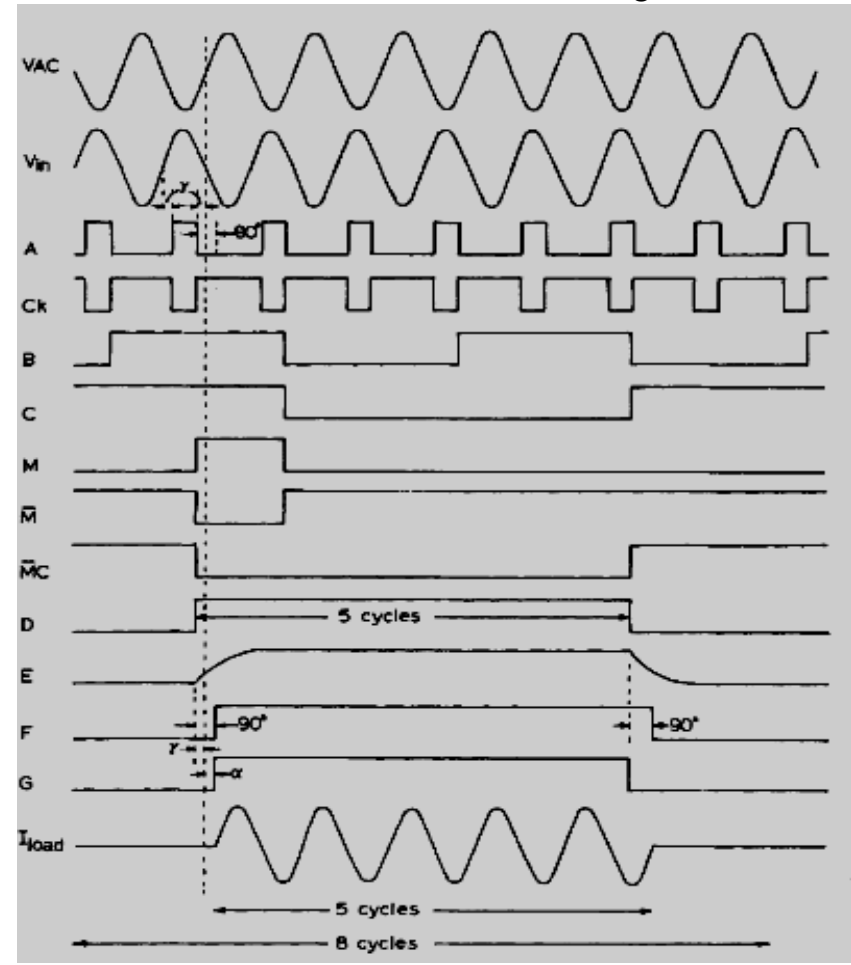

Figure 8: Waveforms of signals at different points in the control circuit.

Fig. 7 shows the power control system block diagram and power control circuit schematic hardware fabrication of the control topology of ICC. Fig. 8 shows the waveform of signals at different points in the control circuit.

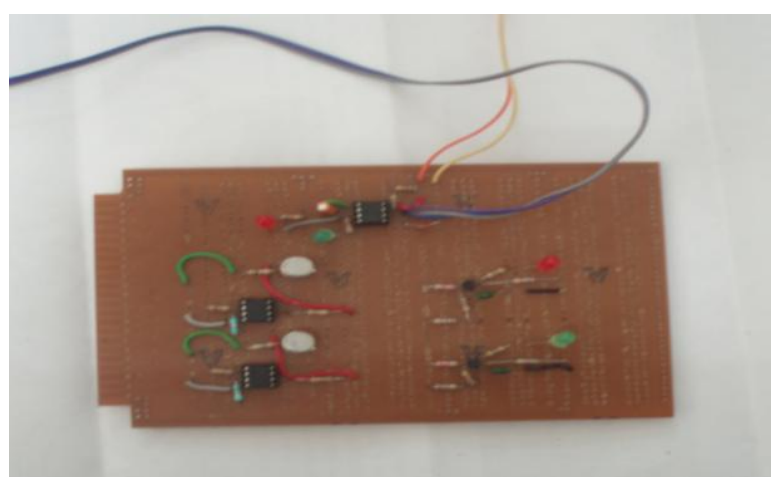

Figure 9: (a) control topology of ICC for R-L load

The 1-Q resistor between the ac supply terminal and MT1 provides the voltage proportional to the load current that is fed into the feedback integrator and averaging circuit. The output of this circuit which is proportional to the dc offset component in the load current goes as a dc reference signal to the inverting input of the comparator. It is noted that when the circuit is initially switched on, $\gamma=0^{\circ}$ and $\alpha=90^{\circ}$, which meets with the requirement of $90^{\circ}$-delayed initial firing of the triac as explained earlier. The effect of the dc reference signal from the feedback circuit is to build up the value of $\gamma$ so as to satisfy

$$
\varphi=\alpha=90^{0}-\gamma
$$

Thereby completely eliminating the dc offset in the load current. In the proposed experiment $600 \mathrm{~V}, 5$ A powers SCR is used. Single phase $1 \mathrm{KW}$ heater is used as the load for the experiment.

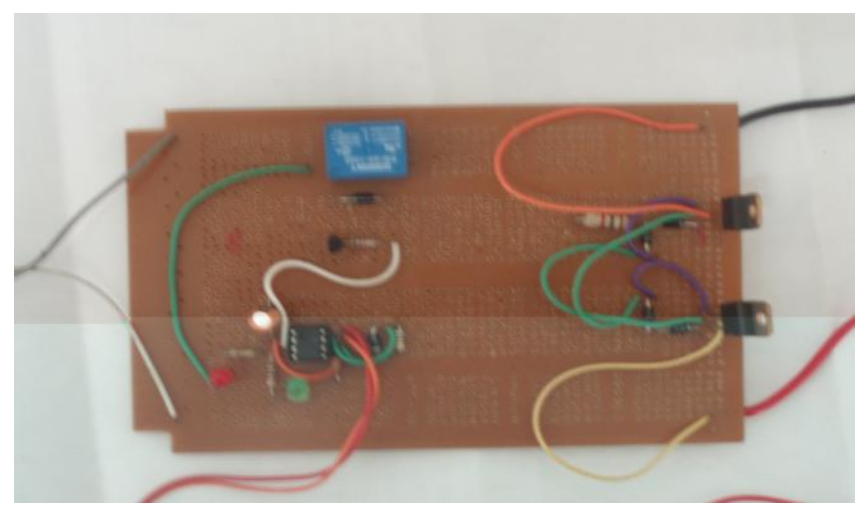

Figure 9: (b) Driver Circuit for ICC for R-L Load

\section{Analysis}

Fig. 9 (a) and Fig. 9 (b) show hardware fabrication of control topology of ICC and Driver circuit for ICC for R-L Load. The power factor is low for the low duty cycle (small value of D), hence ICC is used for the control only without worrying about the efficiency. The power factor and harmonic content are highly unsatisfactory. This type of control is used in heavy machines and heating systems that have high thermal time constants. Fig. 6 (c) shows that the harmonic content is present less that the supply frequency known as inter harmonics. In [6] Group Frequency (GF) is proposed to facilitate the analysis of power system inter harmonics as well as conventional integer harmonics. The concept is applied in the analysis of load currents of ICCs and other controlled power applications. A GF can be generalized for the analysis of load currents or voltages of other power devices. One of the advantages of the GF is that 


\section{International Journal of Science and Research (IJSR) \\ ISSN (Online): 2319-7064}

Index Copernicus Value (2013): 6.14 | Impact Factor (2014): 5.611

a large number of frequency components of a load voltage or current are simplified to a few frequency components without significantly changing the power quality impact of the load current or voltage.

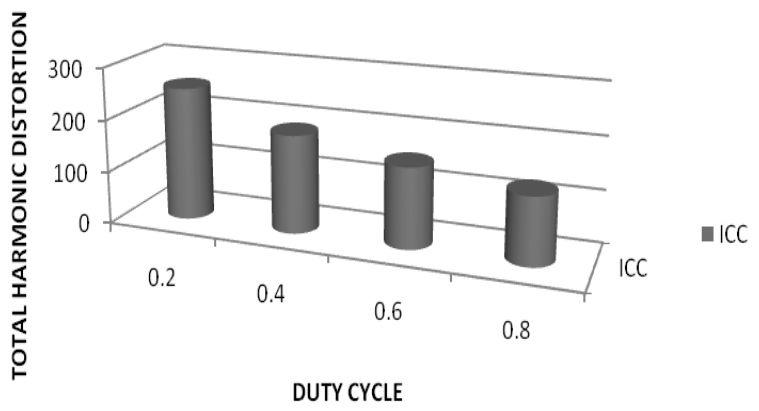

Figure 10: (a) Graph of THD with different duty cycle

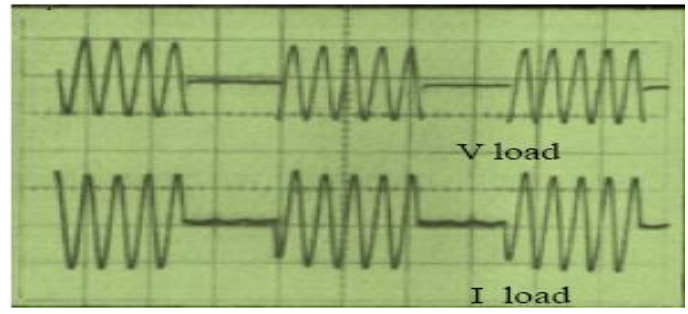

Figure 10: (b). Steady-state voltage and current in R-L load $\alpha=90^{\circ}, \Phi=73^{\circ}$, Irms $=1.33 \mathrm{~A}$, no feedback.

Fig. 10(a) explains the graph of the THD with D while Fig. 10(b) shows the hardware result of steady state voltage and current in R-L load at $\alpha=90^{\circ}, \Phi=73^{\circ}, \mathrm{I}_{\mathrm{rms}}=1.33 \mathrm{~A}$, no feedback. As it evident, the harmonic profile of output voltage waveform is very unsatisfactory. In the further stages, as an improvement of the present circuit can be suggested in future according to requirement and decreases the THD even lower than ICC which better that PCS. For the same power output $125 \%$ reduction in THD is observed. The switching of the switches has been done at zero voltage and current so voltage stresses is reduced.

\section{Applications}

This SSPC is essentially a variable duty cycle switch with zero crossover switching. Unlike normal power controller which operates on the principle of variable phase angle triggering, this circuit switches on power to lad nearly zero crossover points. This controller eminently suited to control of the resistive loads having large thermal hysteresis, e.g. heaters, toaster, soldering irons, oven, cloth iron etc. Inductive loads can be controlled and sophisticated display should be incorporated which displays quantities like current, voltage, duty cycle etc. Higher load can also be controlled by using a triac with larger current rating with suitable heat sink provided. Back to back thyristor pair is also used for the even high power rating. ICC can be used in applications where the process time constant is very large compared to $\mathrm{M} * \mathrm{t} \mathrm{i}$, that is the reason it is very popularly used in resistance spot welders where $M$ is large and it results in good quality welding with uniformity for all jobs.

\section{Conclusion}

Low cost ICC has been simulated, design and implemented for the heating control. As discussed in the different section the harmonic profile of the ICC is improved than PCS. In case of heat controllers of resistive load (R), PCS cause higher order harmonics and generate RFI and heavy inrush currents while switching on from cold. At large power levels, it requires bulky and expensive line filters to minimize RFI. These problems easily overcome by using ICC for heating application. Despite of these advantages, ICC suffering disadvantage of problem of inter harmonic and only suitable to heavy machines and heating systems that have high thermal time constants may reduces the uses of this method. Control circuit is somewhat complex but ease in construction and low hardware cost. The advantage of ICC over Phase Control in respect of reduced RFI is well known. A pronounced disadvantage of ICC, however, in the case of R-L loads was the presence of dc offset in the load current which so far had been eliminated by manual control. The feedback control circuit described in this paper achieves rapid dc offset elimination automatically in all kinds of R-L loads. Its potential can be more effectively utilized in the case of motor loads where there is a situation of rapidly changing power factor. In industrial applications the undesirable feature of speed pulsations in motor loads could possibly be minimized by using flywheels.

\section{References}

[1] M.S.J. Asghar. "Fine power control by discontinuous phase-controlled switching", IEEE Transactions on Circuits and Systems I Fundamental Theory and Applications, 3/1999

[2] S. A. K. Bhat, "Novel control switching schemes for 3phase zero voltage switching," IEEE Trans. Ind. Electron. Contr. Instrum., vol.27, pp. 81-86, May 1980.

[3] M. H. Rashid, Power Electronics, 2nd ed. New Delhi, India: Prentice- Hall of India, 1988.

[4] B. W. Lingard, R. W. Johnson, and W. Shepherd, "Analysis of thyristor controlled single-phase loads with integral-cycle triggering," Proc. Inst. Elect. Eng., vol. 117, no. 2, pp. 607-608, Mar. 1970.

[5] M. S. Beg, M. Mohibullah, M. S. Jamil Asghar, "A circuit for instant controlled switching," Int. J. Electron., vol. 59, pp. 525 -----527, 1985.

[6] Jai P. Agrawal, Power Electronic System Theory and Design, Pearson Education Pvt. Ltd. Ch 10 pp. 355-387.

[7] Yong-Nong Chang, Gwo-Jen Chiou, Shun-Yu Chan, Rong-Ceng Leou, "The Estimation of Interharmonics by Group Frequencies" IEEE Trans. Ind. Electron. Contr. Instrum., vol.27, pp. 224-226, May 2004.

[8] M. Khalifa, Arifur Rahman, and S. Enamul Haque, "Performance of inductive loads fed from ac supply with integral-cycle control," in IEEE Conf Rec. 1977, Twelfth Annul. Meeting IEEE Ind Appl. Soc., pp. 1155-1161. 